\title{
O ESTATUTO DA PESSOA COM DEFICIÊNCIA E A MUDANÇA DA CAPACIDADE LEGAL PARA SER TESTEMUNHA
}

\author{
Alessandro Severino Vallér Zenni ${ }^{1}$ \\ João Lucas Silva Terra ${ }^{2}$
}

\begin{abstract}
RESUMO: O Estatuto da Pessoa com Deficiência ratificou a Convenção Sobre os Direitos das Pessoas com Deficiência, documento internalizado como Emenda Constitucional, alterando substancialmente a legislação interna, rompendo com paradigmas, entre eles a capacidade civil, promovendo a igualdade do deficiente com as demais pessoas. Assim, excluiu a incapacidade do deficiente de ser testemunha, garantindo, inclusive, que lhe é direito o auxílio de tecnologia assistiva para depor. Porém, o Novo Código de Processo Civil contraria o Estatuto e a Convenção, dispondo que o deficiente é incapaz para ser testemunha, o que não deve prevalecer.
\end{abstract}

PALAVRAS-CHAVE: Deficiente; Convenção; Estatuto; Testemunha; Capacidade.

\section{THE STATUTE OF THE DISABLED PERSON AND THE CHANGE OF THE LEGAL CAPACITY TO BE WITNESSED}

\begin{abstract}
The Statute of Persons with Disabilities ratified the Convention on the Rights of Persons with Disabilities, a document internalized as Constitutional Amendment, substantially altering domestic legislation, breaking with paradigms, including civil capacity, promoting equality of the disabled with other persons. Thus, it excluded the incapacity of the disabled to be a witness, even guaranteeing that he is entitled to the aid of assistive technology to testify. However, the New Code of Civil Procedure contradicts the Statute and the Convention, stating that the disabled person is incapable of being a witness, which should not prevail.
\end{abstract}

KEY WORDS: Deficient; Convention; Status; Witness; Capacity.

\section{INTRODUÇÃO}

O presente trabalho tem como escopo analisar a capacidade da pessoa com deficiência, especialmente a sua capacidade para ser testemunha em juízo, cujo objetivo é assegurar o seu acesso à justiça, promovendo a igualdade do deficiente com as demais pessoas.

\footnotetext{
${ }^{1}$ Possui graduação em Direito pela Universidade Estadual de Maringá (1991), mestrado em Direito Negocial com área específica em Trabalho e Processo do Trabalho pela Universidade Estadual de Londrina (1997) e doutorado em Filosofia do Direito pela Pontifícia Universidade Católica de São Paulo (2004). Pós-Doutor na Universidade de Lisboa.

${ }^{2}$ Mestrando em Ciências Jurídicas, área de concentração Direitos da Personalidade, pelo Centro Universitário de Maringá - UNICESUMAR. Pós-graduado em Direito Aplicado pela Escola da Magistratura do Paraná. Graduado em Direito pela Pontifícia Universidade Católica do Paraná, campus Londrina.
} 
Mas, para chegar até a análise da capacidade legal, precisa-se verificar a evolução histórica da pessoa com deficiência até a promulgação do Estatuto da Pessoa com Deficiência, também chamada de Lei Brasileira de Inclusão, Lei n. ${ }^{\circ}$ 13.146/2015, publicada em julho de 2015 e vigente deste janeiro de 2016, qual disciplinou e corroborou com os ideais da Convenção Internacional sobre os Direitos das Pessoas com Deficiência, realizada pela Organização das Nações Unidas, em 2006, na cidade de Nova York.

A sociedade acabou acostumando em segregar os deficientes, sendo que na antiguidade eram mortos. Ocorre que a partir do século XX, especialmente após a Declaração Universal dos Direitos Humanos, as pessoas com deficiência começaram a ser tutelado pelos Estados, assegurando direitos, com o intuído de diminuir o distanciamento entre estes e os que não são deficientes, como forma de promover sua igualdade.

Desta maneira, tanto a Convenção como o Estatuto da Pessoa com Deficiência estão pautados no princípio da dignidade da pessoa humana, da igualdade objetando promover a sua inclusão na sociedade, garantindo a autonomia e a emancipação do deficiente mediante garantias fundamentais.

Como forma de gerar autonomia ao deficiente, que o mesmo seja protagonista de sua vida e norteie o seu caminho, assegurou a Convenção bem como o Estatuto a capacidade legal do deficiente, alterando significativamente o modelo de incapacidade civil, dispondo que a deficiência, por si só, não é mais razão para obstar que a pessoa exerça os atos jurídicos da vida civil por si só.

Assim, antes aqueles que não pudessem exprimir sua vontade, ainda que por causa transitória ou que por enfermidade ou deficiência mental não tivessem o necessário discernimento para a prática dos atos da vida civil estavam impedidos de praticar qualquer ato sem estar representado, sendo, portanto, considerados absolutamente incapaz.

Porém, o Estatuto muda este paradigma, assegurando a capacidade dos deficientes, inclusive para ser testemunha em juízo, não mais prevalecendo a vedação para depor em razão das suas deficiências, afiançando o direito da utilização de tecnologias assistiva, como forma de promover o seu acesso à justiça.

\section{EVOLUÇÃO HISTÓRIA DA PESSOA COM DEFICIÊNCIA ATÉ O ESTATUTO DA PESSOA COM DEFICIÊNCIA:}


As pessoas com deficiência, historicamente, foram segregadas de seus direitos, não eram incluídos na sociedade, não participavam da política, da vida ativa de seu Estado.

$\mathrm{Na}$ Grécia, berço da civilização, dividida em diversas Cidades-Estados, ou seja, a polis, destacam-se Atenas e Esparta, Esparta valorizava o combate, com rigoroso treinamento físico, preparando seus cidadãos a guerra, tendo um caráter militar. E Atenas valorizava a literatura, a filosofia, a educação, buscando um equilíbrio entre corpo e mente. ${ }^{3}$

Tem-se na Grécia, especialmente em Esparta, os primeiros traços da eugenia, mediante uma seleção natural entre os jovens espartanos, uma vez que os garotos eram preparados para o combate físico, aprendendo a utilizar espadas, escudos, e também praticar esportes, de modo que aqueles não conseguiam praticar atividade física ou se militarizar não poderia servir a sua polis e acabavam sendo exterminados.

Na obra A República, de Platão, verifica-se passagens onde é possível constatar a seleção pregada pelos Gregos:

\begin{abstract}
é preciso, de acordo com o que estabelecemos, que os homens superiores se encontrem com as mulheres superiores o maior número de vezes possível, e inversamente, os inferiores com as inferiores, e que se crie a descendência daqueles, e a destes não, se queremos que o rebanho se eleve às alturas, e que tudo isto se faça na ignorância de todos, exceto dos próprios chefes, a fim de a grei dos guardiões estar, tanto quanto possível, isenta de dissensões. ${ }^{4}$
\end{abstract}

Na mesma obra de Platão, verifica-se outra passagem que demonstra a repulsa aos deficientes, embora fosse contrário a morte, defendendo apenas que seres superiores se relacionassem com seres da mesma espécie e aqueles que fossem disformes - deficientes que ficassem isolados, ocultados:

\footnotetext{
- E àqueles dentre os jovens que foram valentes no combate ou em qualquer outro lugar deve dar-se-lhes, entre outros honrarias e prêmios, uma liberdade mais ampla de se unirem às mulheres, a fim de que haja pretexto para se gerar o maior número possível de filhos de homens sessa qualidade.

- Está certo

- Tomarão conta das crianças que forem nascendo as autoridades para esse fim constituídas, quer sejam homens ou mulheres, ou uns e outros, uma vez que os postos de comando são comuns a homens e mulheres...

- Sim.

- Pegarão então nos filhos dos homens superiores, e levá-los-ão para o aprisco, para junto de amas que moram à parte num bairro da cidade; os dos homens inferiores, e
}

\footnotetext{
${ }^{3}$ MALUF, Sahid. Teoria geral do Estado. Atualizador prof. Miguel Alfredo Malufe Neto. - 31. Ed. - São Paulo: Saraiva, 2013, p. 128.

${ }^{4}$ PLATÃO, A República. Tradução Pietro Nassetti. $1^{\text {o }}$ edição. - São Paulo: Martin Claret. 2001, p. 154.
} 
qualquer dos outros que seja disforme, escondê-los-ão num lugar interdito e oculto, como convém.

- ...Se, realmente, queremos que a raça dos guardiões se mantenha pura. ${ }^{5}$

Aristóteles, no livro a Política, também ilustra a segregação realizada pelos gregos:

Quanto a rejeitar ou criar os recém-nascidos, terá de haver uma lei segundo a qual nenhuma criança disforme será criada; com vistas a evitar o excesso de crianças, se os costumes das cidades impedem o abandono de recém-nascidos deve haver um dispositivo legal limitando a procriação; se alguém tiver um filho contrariamente a tal dispositivo, deverá ser provocado o aborto antes que comecem as sensações e a vida (a legalidade ou ilegalidade do aborto será definida pelo critério de haver ou não sensação e vida). ${ }^{6}$

Já em Roma, a Lei das Doze Tábuas, marcante legislação do Estado Romano, formando o cerne da constituição da República Romana ${ }^{7}$, também dispunha sobre a exclusão daquele considerado anormal, onde na tábua IV, que dispunha sobre o pátrio poder e o casamento, facultava ao pai matar o filho que tivesse nascido disforme, mediante o julgamento de cinco vizinhos.

A repulsa que os Romanos tinham contra os deficientes é percebida, inclusive, nas depreciações que realizavam contra seu próprio imperador, já que Tibério Claudius possuía problemas nas pernas, manquejava, conforme assinala Jayme de Altavila:

Tinha o romano uma espécie de obsessão contra os defeitos físicos e não perdoava até mesmo aqueles que chegavam à suprema autoridade, como o imperador Claudius, que sempre foi ridicularizado pela sua manqueira ou claudicância. ${ }^{8}$

Mas é no próprio Estado Romano, qual se caracterizou, além das grandes conquistas territoriais, com o surgimento e ascensão do cristianismo, que as pessoas com deficiência passaram a ser toleradas pela sociedade e deixaram de ter suas vidas ceifadas.

Maria Aparecida Gugel explica a tolerância dos romanos;

Foi no vitorioso Império Romano que surgiu o cristianismo. A nova doutrina voltava-se para a caridade e o amor entre as pessoas. As classes menos favorecidas sentiram-se acolhidas com essa nova visão. O cristianismo combateu, dentre outras

\footnotetext{
${ }^{5}$ Ibid, p. 155.

${ }^{6}$ ARISTÓTELES, A política. Tradução: Pedro Constantin Tolens, $3^{\mathrm{a}}$ reimpressão, São Paulo : Editora Martin Claret, 2010, p. 1335b.

${ }^{7}$ http://www.stf.jus.br/portal/cms/verTexto.asp?servico=bibliotecaConsultaProdutoBibliotecaSimboloJustica\&pa gina=tabuas. Acesso em 08.mai.2017.

${ }^{8}$ ALTAVILA, Jayme de. Origem dos Direitos dos Povos. - $12^{\text {a }}$ edição. - São Paulo: Ícone, 2013, p. 94.
} 
práticas, a eliminação dos filhos nascidos com deficiência. Os cristãos foram perseguidos, porém, alteraram as concepções romanas a partir do Século IV. Nesse período é que surgiram os primeiros hospitais de caridade que abrigavam indigentes e pessoas com deficiências. 9

Em razão do surgimento e evolução do Cristianismo ${ }^{10}$, com o fortalecimento da Igreja Católica, as pessoas com deficiência passaram a ser toleradas nas sociedades, isto é, deixaram de ser eliminadas em razão das suas incapacidades ou limitações. No entanto, as pessoas com deficiência eram vistas como seres castigados por Deus, seres possuídos, demoníacos, que estariam pagando por algum pecado, além de servirem como diversão para os nobres.

Assim aponta Adreana Dulcina Platt:

\begin{abstract}
$\mathrm{Na}$ Idade Média, a questão da bruxaria/feitiçaria emergiria de forma mais contundente, haja vista o domínio absoluto da Igreja Católica nas questões da sociedade sob um amplo aspecto, não mais sob a alegação da vontade de deuses, mas na presumida manifestação demoníaca em indivíduos que não se moldassem às vontades da corte e do clero.

Podemos descrever que o deficiente, nesse período, era considerado um indivíduo, por natureza, possesso por entidades malignas. ${ }^{11}$
\end{abstract}

Contudo, é no próprio período da idade média que houve uma expansão, ainda que desordenada e sem qualidade, no atendimento as pessoas com deficiência, com o surgimento de novos hospitais, abrigos.

Nesse período, ainda, a partir do século XIII, XIV que se inicia na Europa uma forte expansão de instituições destinadas a acolher as pessoas com algum tipo de deficiência, conquanto esses indivíduos passaram a ficar enclausurados. ${ }^{12}$

Não obstante toda essa tolerância da sociedade em face das pessoa com deficiência em razão do Cristianismo, Michael Foucault ainda aponta que ocorria o abandono de indivíduos

\footnotetext{
${ }^{9}$ GUGEL, Maria Aparecida. A pessoa com deficiência e sua relação com a história da humanidade. Disponível em: http://www.ampid.org.br/ampid/Artigos/PD_Historia.php. Acesso em 16.abr.2017.

${ }^{10}$ Rosimery Leão Mondaini assevera que com o Cristianismo, o homem passou a ser visto como ser racional, criação e manifestação de Deus. MONDAINI, Rosimery Leão. HISTÓRIA DA DEFICIENCIA E DA EDUCAÇÃO ESPECIAL: NO BRASIL E NO MARANHÃO. V Congresso Brasileiro Multidisciplinar de Educação Especial. 3 a 6 de novembro de 2009 - Londrina - Pr, p. 1618. Disponível em: http://www.uel.br/eventos/congressomultidisciplinar/pages/arquivos/anais/2009/195.pdf. $\quad$ Acesso em 16.abr. 2016.

11 PLATT, Adreana Dulcina. Uma Contribuição Histórico- Filosófica para a análise do Conceito de Deficiência. Ponto de Vista: Revista de Educação e Processos Inclusivos, Florianópolis, SC, Brasil v. 1 • n. 1 • julho/dezembro de 1999, p. $72 . \quad 7$ Disponível em: https://periodicos.ufsc.br/index.php/pontodevista/article/view/1523. Acesso em 17.abr.2017.

${ }^{12}$ ARANHA, Maria Salete Fábio. Projeto Escola Viva: garantindo o acesso e permanência de todos os alunos na escola: necessidades educacionais especiais dos alunos, volume 1. - Brasília: Ministério da Educação, Secretaria de Educação Especial, 2005, p. 9.
} 
considerados loucos, no "Nau dos loucos", que eram barcos que levavam as "cargas insanas", ou seja, as pessoas com deficiência intelectual eram abandonadas de uma cidade à outra, levando uma vida nômade. ${ }^{13}$

Mas, é na idade moderna, caracterizada pelo renascentismo cultural, pela rescisão com o teocentrismo e principalmente pela Revolução Francesa, emerge o assistencialismo as pessoas com deficiência, uma vez que há grande avanço na criação de hospitais, escolas, lares a fim de atender as pessoas com deficiência, rompendo assim, com uma visão espiritual para uma ótica médica, com possibilidade de tratamento.

Assim, a idade moderna fica marcada também pelos inventos tecnológicos, pelos avanços médicos e educacionais, em especial aos deficientes, preocupando-se com a leitura e escrita desses indivíduos, surgindo diversas técnicas que buscaram auxiliar sua alfabetização.

Maria Aparecida Gugel assinala quanto a este período:

Os séculos XVII e XVIII trazem avanços no campo do conhecimento filosófico, médico e educacional, ocupando-se com a necessidade de preparo da mão-de-obra para a produção; surgem as primeiras iniciativas de ensino de comunicação para pessoas surdas; instituições para cuidar e tratar de pessoas com deficiência mental; Louis Braille cria o código Braille para as pessoas cegas; desenvolvem-se os inventos de ajuda, tais como, cadeiras de rodas, bengalas, muletas, próteses, entre outros instrumentos de apoio. ${ }^{14}$

O período moderno se caracterizou, em relação as pessoas com deficiência, pela transição de uma visão religiosa para uma visão médica, com tratamentos, recuperação, criando mecanismos que possibilitasse a reabilitação e alfabetização do deficiente.

No entanto, é no século XX, embora tenha sido o período com as maiores atrocidades da humanidade, que as pessoas, incluindo os deficientes, passaram a ser o centro do direito e do Estado, norteando as políticas públicas.

Maria Aparecida Gugel aduz sobre esse século:

O Século XX trouxe avanços importantes para as pessoas com deficiência, sobretudo em relação às ajudas técnicas ou elementos tecnológicos assistivos. Os instrumentos que já vinham sendo utilizados cadeira de rodas, bengalas, sistema de ensino para surdos e cegos, dentre outros foram se aperfeiçoando. A sociedade, não

\footnotetext{
${ }^{13}$ FOUCAULT, Michel. História da loucura na Idade Clássica. Trad. José Teixeira Coelho Netto. São Paulo: Perspectiva, 1978. p. 13.

${ }^{14}$ GUGEL, Maria Aparecida. Pessoas com deficiência e o direito ao concurso público: reserva de cargos e empregos públicos, administração pública direta e indireta. Goiânia : Ed. da UCG, 2006, p. 26.
} 
obstante as sucessivas guerras, organizou-se coletivamente para enfrentar os problemas e para melhor atender a pessoa com deficiência. ${ }^{15}$

Em razão da I e II Guerra Mundial, qual deixou inúmeras pessoas incapacitadas, em especial fisicamente, é no século XX que as pessoas com deficiência começam a ter seus direitos reconhecidos, serem tratados como pessoas, principalmente pelas Convenções e Tratados Internacionais, citando-se como mais relevante a Declaração Universal dos Direitos Humanos - DUDH, qual é uma recomendação aos Estados.

Ricardo Tadeu Marques da Fonseca, primeiro juiz cego da história do Brasil, assinala acerca da Declaração Universal dos Direitos Humanos:

Desde a Declaração Universal dos Direitos Humanos, de 1948, a Organização das Nações Unidas vem aperfeiçoando, por meio de seus tratados internacionais, o processo de edificação dos Direitos Humanos, o qual se universalizou a partir da primeira metade do Século XX, para fazer frente aos abusos havidos no período das Guerras Mundiais e aos que foram cometidos posteriormente até os nossos dias. ${ }^{16}$

Referida Declaração, proclamada em 10/12/1948, na cidade de Paris, embora não dispôs especificamente sobre as pessoas com deficiência ${ }^{17}$, tem como propósito a defesa da pessoa - do ser humano - realçando sua importância, reverberando os seus Direitos, conciliando princípios inerentes ao homem, a dignidade, igualdade e liberdade. ${ }^{18}$

Diversos tratados internacionais passaram a ser proclamadas a fim de garantir direitos fundamentais das pessoas com deficiência, mas o principal documento é a Convenção Internacional sobre os Direitos da Pessoa com Deficiência, realizada pela Organização das Nações Unidas - ONU, firmada pela assembleia da ONU em 13 de dezembro de 2006, na cidade de Nova York, e assinada pelos países em 30 de março de 2007, onde o Brasil foi um dos signatários e incorporou referido documento ao Estado interno.

A Convenção sobre os Direitos da Pessoa com Deficiência entrou em vigência no Estado Brasileiro em 2009, quando o Presidente da República, Luis Inácio Lula da Silva, através do Decreto n. ${ }^{\circ} 6.949$, de 25 de agosto de 2009, promulgou-a.

\footnotetext{
${ }^{15}$ GUGEL, Maria Aparecida. A pessoa com deficiência e sua relação com a história da humanidade. Disponível em: http://www.ampid.org.br/ampid/Artigos/PD_Historia.php. Acesso em 16.abr.2017.

${ }^{16}$ FONSECA. Ricardo Tadeu Marques da. A ONU e seu conceito revolucionário de pessoa com deficiência. Revista Ltr. Legislação do Trabalho, v. 72-I, p. 263-270. 2009.

${ }^{17}$ Não obstante a Declaração Universal dos Direitos Humanos não ter disposto expressamente sobre a pessoa com deficiência, a DUDH menciona o termo invalidez, no seu art. XXV, o que, por certo, refere-se aos deficientes.

${ }^{18}$ FACHIN, Zulmar. Curso de direito constitucional. - 3. ed. rev. atual. e ampliada. - São Paulo: Método, 2008, p. 197.
} 
A convenção foi internalizada ao arcabouço jurídico após a aprovação pelo Congresso Nacional através do Decreto Legislativo n. ${ }^{\circ}$ 186, de 9 de julho de 2008, além de ter sido depositado o instrumento de ratificação junto à Organização das Nações Unidas, em $1^{\circ}$ de agosto de 2008 e promulgada em 25 de agosto de 2009, através do decreto do Decreto n. ${ }^{\circ}$ 6.949.

Tal convenção, por ter natureza de direitos humanos, ingressou no ordenamento jurídico brasileiro como Emenda à Constituição, conforme preconiza o $\S 3^{\circ}$, do art. $5^{\circ}$, acrescentado pela Emenda Constitucional n. ${ }^{\circ}$ 45, de 08/12/2004, uma vez que foi aprovada pelo quórum qualificado, isto é, por $3 / 5$ (três quintos) em dois turnos, em cada casa legislativa.

E mais, a Convenção é o único tratado, até o momento, adentrado ao corpo jurídico brasileiro como Emenda Constitucional, já que foi o único aprovado dentro do quórum qualificado. ${ }^{19}$ Os demais Tratados Internacionais de Direitos Humanos são considerados como normas supralegal, quer dizer, estão entre a Constituição Federal e as demais normas infraconstitucionais.

A Convenção expressamente dispõe que os Estados Membros poderão adotar medidas especiais imprescindíveis que visem acelerar ou alcançar a igualdade de fato das pessoas com deficiência com as demais, conforme se extrai do art. $5^{\circ}$, parágrafo $4^{\circ}$. Impõe, ainda, a Convenção, no seu art. $4^{\circ}$, que os Estados-partes adotem medidas legislativas, criando ou revogando leis e/ou regulamentando-os a fim de assegurar e promover o pleno exercício de todos os direitos humanos e liberdades fundamentais das pessoas com deficiência.

Com isto, em 6 de julho de 2015, o Estado Brasileiro instituiu o Estatuto da Pessoa com Deficiência, através da Lei ordinária n. ${ }^{\circ}$ 13.146, também chamada de Lei Brasileira de Inclusão da Pessoa com Deficiência, entrando em vigor em janeiro de 2016, inaugurando uma nova era para os deficientes e para toda a sociedade, inferindo e modificando diversas áreas do ordenamento jurídico interno, além de ratificar a Convenção.

Acerca do Estatuto, assevera Luiz Alberto David Araujo:

\footnotetext{
${ }^{19}$ Laís de Figueirêdo Lopes assevera nesse sentido: "Assim, a Convenção sobre os Direitos das Pessoas com Deficiência, juntamente com seu Protocolo Facultativo, passou a ser o primeiro tratado internacional de direitos humanos adotado pelo Brasil após a Emenda Constitucional n. 45/2004 com equivalência formal a uma emenda constitucional. LOPES, Laís de Figueirêdo. Comentários ao Estatuto da Pessoa com Deficiência / coordenação de Flávia Piva Almeida Leite, Lauro Luiz Gomes Ribeiro e Waldir Macieira de Costa Filho. - São Paulo: Saraiva, 2016, p. 41.
} 
A ideia de um "Estatuto da Pessoa com Deficiência" dá à lei uma dimensão de unidade, de sistematização, interferindo em diversos diplomas. Para a efetivação da Convenção da ONU sobre os Direitos das Pessoas com Deficiência, foi necessário alterar o Código Civil, o Código de Processo Civil, o Código Penal, para que novos tratamentos fossem redesenhados e as novas visões determinadas pela Convenção integradas, de forma objetiva, na referida legislação. Isso explica o cuidado do prazo de seis meses para sua entrada em vigor nos termos do seu art. $127 .^{20}$

O Estatuto foi elaborado, reunindo diversos temas que já estavam previstos no ordenamento jurídico e inovando em outros aspectos, pautando-se pela igualdade, oportunidade, inclusão, socialização, não discriminação, entre outros ideários que consagram o princípio da dignidade da pessoa humana.

Nesse sentido, assinala Pablo Stolze: "Pela amplitude do alcance de suas normas, o Estatuto traduziu uma verdadeira conquista social, ao inaugurar um sistema normativo inclusivo, que homenageia o princípio da dignidade da pessoa humana em diversos níveis." 21

\section{MUDANÇA DA CAPACIDADE CIVIL:}

O Estatuto da Pessoa com Deficiência e a própria Convenção sobre os Direitos da Pessoa com Deficiência romperam com paradigmas até então estabelecidas no ordenamento jurídico, modificaram legislações e criou novas previsões legais, tanto na seara cível, penal, previdenciária, trabalhista e processual civil.

Entre as mudanças radicais operadas pelo Estatuto e pela Convenção se dá acerca da capacidade da pessoa deficiente para praticar os atos da vida civil, alterando, substancialmente a incapacidade, ou melhor, a capacidade de fato ou de exercício.

A capacidade, consoante lição de Maria Helena Diniz, integra e tem a sua medida na personalidade $^{22}$. Personalidade, pode ser compreendida sob duas vertentes: i) uma como o conjunto de atributos que formam uma pessoa; e ii) como a aptidão genética que todo ser humana tem para contrair direitos e deveres, sendo esta considerada a personalidade jurídica.

A personalidade jurídica, conforme Pablo Stolze Gagliano e Rodolfo Pamplona Filho é:

\footnotetext{
${ }^{20}$ ARAUJO, Luiz Alberto David. COSTA FILHO, Waldir Macieira da. O estatuto da pessoa com deficiência EPCD (LEI 13.146, DE 06.07.2015): Algumas Novidades. Revista dos Tribunais, vol. 962/2015, p. 65 - 80, Dez / 2015.

${ }^{21}$ STOLZE, Pablo. É o fim da interdição?. Revista Jus Navigandi, ISSN 1518-4862, Teresina, ano 21, n. 4605, 9 fev. 2016. Disponível em: 〈https://jus.com.br/artigos/46409>. Acesso em: 15.mai.2017.

${ }^{22}$ DINIZ, Maria Helena. Curso de direito civil brasileiro, v. 1: teoria geral do direito civil. - 23. ed. rev. e atual. - São Paulo : Saraiva, 2006, p. 147.
} 
Personalidade jurídica é a aptidão genérica para titularizar direitos e contrair obrigações, ou, em outras palavras, é o atributo para ser sujeito.

Adquirida a personalidade, o ente passa a atuar, na qualidade de sujeito de direito (pessoa natural ou judicia), praticando atos e negócios jurídicos dos mais diferentes matizes. $^{23}$

E a personalidade jurídica, que permite que a pessoa seja sujeito de direitos ou adquira deveres, se dá com o nascimento com vida, ainda que este tenha vivido por pouquíssimos segundos, conforme preconiza o art. 2 do Código Civil.

A teoria adotada pelo legislador, em tese, ao prescrever que a personalidade se inicia com o nascimento com vida, foi a teoria natalista, não obstante pôr a salvo os direitos do nascituro. Com isto, a doutrina acrescenta mais duas teorias quando ao início da personalidade, a teoria da personalidade condicional e a teoria concepcionista.

A teoria natalista é aquela que reconhece o início da personalidade com o nascimento com vista, concluindo que o nascituro tem apenas expectativa de direito.

Já a teoria da personalidade condicional também reconhece que a personalidade se dá com o nascimento com vida, mas que o nascituro está sob uma condição suspensiva, onde esta condição é justamente o nascimento.

Por sua vez, a terceira teoria e ora mais aceita pela doutrina e jurisprudência, é que a teoria concepcionista, onde a personalidade se dá desde a concepção, considerando, portanto, o nascituro como pessoa, sendo titular de direitos.

Sustenta essa teoria a previsão do nascituro já ter direitos da personalidade, uma vez que é tutelado à sua vida pelo Estado, bem como direitos patrimoniais, onde é possível, por exemplo, realizar doação ao nascituro.

Pois bem, a capacidade é adquirida justamente com a personalidade jurídica, de modo que toda pessoa passa a ter uma capacidade jurídica, que segundo Cristiano Chaves e Nelson Rosenvald é "a aptidão para adquirir direitos e assumir deveres pessoalmente". ${ }^{24}$

Assim, capacidade jurídica se fraciona em capacidade política e em capacidade civil $^{25}$, onde essa se divide em capacidade de direito ou também chamada de aquisição ou de gozo,

\footnotetext{
${ }^{23}$ GAGLIANO, Pablo Stolze. PAMPLONA FILHO, Rodolfo. Manual de direito civil; volume único. - São Paulo: Saraiva, 2017, p. 41.

${ }^{24}$ FARIAS, Cristiano Chaves de. ROSENVALD, Nelson. Curso de direito civil: parte geral e LINDB. - 14. ed. rev., ampl. e atual. - Salvador: Ed. JusPodivm, 2016, p. 319.

${ }^{25}$ DONIZETTI, Elpídio. QUINTELLA, Felipe. Curso didático de direito civil. - 3. ed. - São Paulo, Atlas, 2014, p. 48.
} 
sendo que esta é reconhecida a todos, inerente a própria personalidade da pessoa, e capacidade de fato ou de exercício, considerada como a aptidão para a pessoa praticar, por si só, os atos da vida civil.

Flávio Tartuce assim diferencia Capacidade:

- Capacidade de direito ou de gozo - é aquela comum a toda pessoa humana, inerente à personalidade, e que só se perde com a morte prevista no texto legal, no sentido de que toda pessoa é capaz de direitos e deveres na ordem civil (art. $1 .^{\circ}$ do CC)

- Capacidade de fato ou de exercício - é aquela relacionada com o exercício próprio dos atos da vida civil. ${ }^{26}$

Com isto, todos possuem capacidade de direito, já que é própria da personalidade, sendo considerado a aptidão genérica para contrair direitos e deveres. E tendo também a capacidade de fato ou de exercício, que é a possibilidade de praticar sozinhos os próprios atos da vida civil, terá a pessoa a capacidade jurídica plena, designada também de geral ou civil, qual engloba, assim, a capacidade de direito mais a capacidade de fato.

Recorre-se novamente a lição de Cristiano Chaves e Nelson Rosenvald:

\begin{abstract}
A capacidade jurídica plena ou geral é reconhecida a quem dispõe tanto da capacidade de direito, quanto da capacidade de fato. Em outras palavras: a plena capacidade jurídica, então, correspondente à efetiva possibilidade, concedida pela ordem jurídica, de que o titular de um direito atue, no plano concreto, sozinho, sem qualquer auxílio de terceiros. $^{27}$
\end{abstract}

Toda pessoa possui capacidade de direito, qual é atribuída a toda pessoa, mas nem todos têm a capacidade de exercício ou de fato, vez que alguns, em razão de critérios etários ou psicológicos, não possuem condições de exercitar os atos da vida civil sem o auxílio de outra pessoa que tenha capacidade plena, considerando, assim, um incapaz.

Carlos Roberto Gonçalves ensina:

Nem todas as pessoas têm, contudo, a capacidade de fato, também denominada capacidade de exercício ou de ação, que é a aptidão para exercer, por si só, os atos da vida civil. Por faltarem a certas pessoas alguns requisitos materiais, como maioridade, saúde, desenvolvimento mental etc., a lei, com o intuito de protege-las, malgrado não lhes negue a capacidade de adquirir direitos, sonega-lhes o de se

\footnotetext{
${ }^{26}$ TARTUCE, Flávio. Direito civil, 1 : Lei de introdução e parte geral. - 9. ed. - Rio de Janeiro : Forense; São Paulo: Método, 2013, p. 125.

${ }^{27}$ FARIAS, Cristiano Chaves de. ROSENVALD, Nelson. Op. cit., p. 319.
} 
autodeterminarem, de os exercer pessoal e diretamente, exigindo sempre a participação de outra pessoa, que as representa ou assiste. ${ }^{28}$

Adiante, Carlos Roberto Gonçalves conclui: “quem só ostenta a de direito, tem capacidade limita e necessita, como visto, de outra pessoa que substitua ou complete a sua vontade são, por isso, chamados de 'incapazes'."29

A incapacidade é conceituada por Pablo Stolze da seguinte maneira:

Em linha de princípio, cumpre mencionar, mais uma vez, que a previsão legal da incapacidade traduz a falta de aptidão para praticar pessoalmente atos da vida civil. Encontra-se nessa situação a pessoa a quem falte capacidade de fato ou de exercício, ou seja, que esteja impossibilidade de manifestar rela e juridicamente a sua vontade. $^{30}$

Ademais, a incapacidade pode ser dividida em capacidade absoluta ou incapacidade relativa. A absoluta refere-se àqueles que não possuem condições alguma de exercer atos civis por si só, devendo ser representados, sob pena do seu ato ser considerado nulo. Já os relativamente incapazes só podem praticar ato jurídico caso estejam assistidos, sob pena de ser anulável o negócio, vez que sua vontade já tem relevância.

Maria Helena Diniz assim conceitua incapacidade absoluta e incapacidade relativa:

A incapacidade será absoluta quando houver proibição total do exercício do direito pelo incapaz, acarretando, em caso de violação do preceito, a nulidade do ato (CC, art. 166, I). Logo, os absolutamente incapazes têm direitos, porém não poderão exercê-los direta ou pessoalmente, devendo ser representados. ${ }^{31}$

E Maria Helena Diniz complementa:

A incapacidade relativa diz respeito àqueles que podem praticar por si os atos da vida civil desde que assistidos por quem o direito positivo encarrega deste ofício, em razão de parentesco, de relação de ordem civil ou de designação judicial. O efeito da violação desta norma é gerar a anulabilidade do ato jurídico (CC, art. 171, I), dependendo de iniciativa do lesado, havendo até hipóteses em que poderá ser confirmado ou ratificado tal ato praticado por relativamente incapaz sem a assistência de seu representante. ${ }^{32}$

\footnotetext{
${ }^{28}$ GONÇALVES, Carlos Roberto. Direito civil brasileiro : parte geral : v 1. - São Paulo: Saraiva, 2003, p. 72.

${ }^{29}$ Ibid, p. 72.

${ }^{30}$ GAGLIANO, Pablo Stolze. PAMPLONA FILHO, Rodolfo. Op. cit., p. 48.

${ }^{31}$ DINIZ, Maria Helena. Op. cit., p. 152.

${ }^{32}$ Ibid, p. 166-167.
} 
Ou seja, a capacidade para exercer os atos da vida civil é a regra e a incapacidade, seja absoluta ou relativa, a exceção, justamente porque a vedação a prática de determinados atos se dá apenas para determinadas pessoas em razão de critérios etário ou psicológico, sendo que tais disposições são cogentes, de ordem pública, interessando a toda coletividade.

Desta maneira, até o Estatuto da Pessoa com Deficiência, tinha-se que o absolutamente incapaz, conforme disposição no art. $3^{\circ}$ do Código Civil eram: i) os menores de dezesseis anos; ii) os que por enfermidade ou deficiência mental não tivessem o necessário discernimento para a prática dos atos da vida civil; iii) e aqueles que não pudessem exprimir sua vontade, ainda que por causa transitória.

Já os relativamente incapazes eram: i) os que por deficiência mental tinham o discernimento reduzido; ii) os excepcionais, sem desenvolvimento mental completo; iii) além dos maiores de dezesseis e menores de dezoito anos; iv) os ébrios habituais e os viciados em tóxicos; v) e os pródigos.

No entanto, pautados no princípio da dignidade da pessoa humana e da igualdade, o Estatuto e a própria Convenção reconstroem o conceito de capacidade civil, ao afirmarem que os deficientes terão igualdade de condições e de capacidade com as demais pessoas.

A Convenção assim estipulou no art. 12, item 2: “2. Os Estados Partes reconhecerão que as pessoas com deficiência gozam de capacidade legal em igualdade de condições com as demais pessoas em todos os aspectos da vida." 33

Já o Estatuto prescreve em seu art. 84 que: “Art. 84. A pessoa com deficiência tem assegurado o direito ao exercício de sua capacidade legal em igualdade de condições com as demais pessoas. $^{34}$

Ou seja, a Convenção e o Estatuto modificaram toda a previsão da capacidade civil, reconhecendo que a simples deficiência não é mais critério para determinar a incapacidade do sujeito, assegurando, desta maneira, que os deficientes têm a plena capacidade civil, podendo praticar os atos da vida civil por si só.

Carolina Valença Ferraz e Glauber Salomão Leite, ao comentarem sobre a mudança imposta pelo Estatuto da Pessoa com Deficiência, assinada:

Portanto, eventuais dificuldades no desempenho de movimentos, de comunicação ou de outras espécies não podem ser confundidas com falta de capacidade para tomar

\footnotetext{
${ }^{33}$ http://www.planalto.gov.br/ccivil 03/ ato2007-2010/2009/decreto/d6949.htm. Acesso em: 15.mai.2017.

34 http://www.planalto.gov.br/ccivil_03/ ato2015-2018/2015/lei/113146.htm. Acesso em: 15.mai.2017.
} 
decisões. É certo que, na quase totalidade dos casos, feitas as adaptações apropriadas, a pessoa com deficiência estará apta a manifestar sua vontade e a expressar seu querer.

Nesse sentido, a LBI estabelece que, em regra geral, toda pessoa com deficiência tem capacidade para exercer os seus direitos. Vale observar que a lei não faz distinção quanto ao tipo de deficiência, de modo que estão incluídas nesse preceito as pessoas com deficiência mental e intelectual. ${ }^{35}$

Cleide Ramos ao comentar a Convenção sobre os Direitos das Pessoas com deficiência, assevera:

A reafirmação de que as pessoas com deficiência devem ser reconhecidas como pessoas, implica no reconhecimento de que possuem capacidade de usufruir e exercer direitos em todos os aspectos da vida. Com isso, provoca uma ruptura na clássica separação que reconhecia a todos os seres humanos a capacidade de direito, consistente em usufruir de todos os direitos e liberdades fundamentais, ao passo que limitava a capacidade de exercício desses direitos em razão da condição de deficiência. ${ }^{36}$

Diante das alterações imposta pelo Estatuto da Pessoa com Deficiência e pela Convenção, as previsões legais que estabelecem as incapacidades, absoluta e relativa, respectivamente, artigos $3^{\circ}$ e $4^{\circ}$ do Código Civil, passaram a ter a seguinte redação:

\footnotetext{
Art. $3^{\circ}$ São absolutamente incapazes de exercer pessoalmente os atos da vida civil os menores de 16 (dezesseis) anos.

Art. $4^{\circ}$ São incapazes, relativamente a certos atos ou à maneira de os exercer:

I - os maiores de dezesseis e menores de dezoito anos;

II - os ébrios habituais e os viciados em tóxico;

III - aqueles que, por causa transitória ou permanente, não puderem exprimir sua vontade;

IV - os pródigos.

Parágrafo único. A capacidade dos indígenas será regulada por legislação especial. ${ }^{37}$
}

Com isto, o absolutamente incapaz é apenas o menor de 16 (dezesseis) anos. Não há mais incapacidade pautada na deficiência metal ou intelectual da pessoa. Tem-se, ainda, a incapacidade relativa para aqueles que não puderem exprimir sua vontade, ainda sim, devendo ser submetido a um processo de curatela, qual afetará apenas os atos relacionados aos de direito de natureza patrimonial e negocial, consoante previsão do art. 85, do Estatuto.

35 FERrAZ, Carolina Valença. LEITE, Glauber Salomão. Comentários ao Estatuto da Pessoa com Deficiência / coordenação de Flávia Piva Almeida Leite, Lauro Luiz Gomes Ribeiro e Waldir Macieira de Costa Filho. - São Paulo: Saraiva, 2016, p. 79.

${ }^{36}$ RAMOS, Cleide. A Convenção sobre os Direitos das Pessoas com Deficiência Comentada. Coordenação de Ana Paula Crosara Resende e Flavia Maria de Paiva Vital _ Brasília : Secretaria Especial dos Direitos Humanos. Coordenadoria Nacional para Integração da Pessoa Portadora de Deficiência, 2008, p. 57.

${ }^{37}$ http://www.planalto.gov.br/ccivil_03/leis/2002/L10406.htm. Acesso em 16.mai.2017. 
Ou seja, houve uma ruptura quanto a incapacidade, sendo que antes o deficiente mental ou intelectual e aqueles que não pudessem exprimir sua vontade eram considerados absolutamente incapaz, não podiam praticar atos da vida civil sozinho, mesmo possuindo mais de 18 anos, pois entendia que lhe faltava a compreensão do negócio jurídico.

Agora possuem capacidade para os atos, já que a ordem jurídica deve promover a igualdade entre aqueles que tem e não tem deficiência a fim de permitir uma convivência justa e solidária entre as pessoas.

\section{DA CAPACIDADE LEGAL DO DEFICIENTE PARA SER TESTEMUNHA:}

A prova testemunhal serve para colher o depoimento das testemunhas quando os fatos não puderem ser provados de outra forma ou quando pairar dúvidas quanto a comprovação da matéria ou ser imprescindível a declaração de terceiros que tenham conhecimento sobre o assunto fático em litigio.

Ocorre que a Convenção e o Estatuto ao promoverem a igualdade, ao igualarem a capacidade legal do deficiente, também alteraram a vedação antes imposta às pessoas com deficiência para serem testemunhas.

Com isto, os incisos II e III, do artigo 228 do Código Civil que antes proibia que as pessoas com enfermidade ou retardamento mental, não tivessem o discernimento para a prática dos atos da vida civil, bem como os cegos e surdos, quando a ciência do fato que se quer provar dependa dos sentidos que lhes faltam, não fossem admitidos como testemunha, agora devem.

Assim, o art. 228 do Código Civil possui a seguinte redação:

Art. 228. Não podem ser admitidos como testemunhas:

I - os menores de dezesseis anos;

II - (Revogado); (Redação dada pela Lei no 13.146, de 2015) (Vigência)

III - (Revogado); (Redação dada pela Lei no 13.146, de 2015) (Vigência)

IV - o interessado no litígio, o amigo íntimo ou o inimigo capital das partes;

$\mathrm{V}$ - os cônjuges, os ascendentes, os descendentes e os colaterais, até o terceiro grau de alguma das partes, por consangüinidade, ou afinidade.

$\S 1$ 1o Para a prova de fatos que só elas conheçam, pode o juiz admitir o depoimento das pessoas a que se refere este artigo.

§ 2o A pessoa com deficiência poderá testemunhar em igualdade de condições com as demais pessoas, sendo-lhe assegurados todos os recursos de tecnologia assistiva. ${ }^{38}$

${ }^{38}$ http://www.planalto.gov.br/ccivil_03/leis/2002/L10406.htm. Acesso em 16.mai.2017 
E mais, o Estatuto além revogar os dispositivos que vedavam a pessoa com deficiência ser testemunha, ainda inovou e institui $\S 2^{\circ}$, do artigo supra, acrescentando que o deficiente poderá testemunhar em igualdade de condições com as outras pessoas, sendo um direito seu o auxílio de instrumentos que facilitem seu depoimento.

Flávio Tartuce assim comenta o artigo 228, do Código Civil:

De toda sorte, houve a revogação expressa dos incisos II e III deste art. 228 do CC pela Lei n. ${ }^{\circ}$ 13.146/2015, que instituiu o Estatuto da Pessoa com Deficiência, cujo objetivo foi a plena inclusão das pessoas com deficiência, na linha da Convenção de Nova York, tratado internacional de direitos humanos do qual o Brasil é signatário e que tem força de Emenda à Constituição. Tal revogação segue a linha de conteúdo das modificações dos arts. $3^{\circ}$ e $4^{\circ}$ da codificação material, com os mesmos objetivos. Assim, não existem mais no sistema civil as normas que comiseravam impossibilidades para depor como testemunhas aqueles que, por enfermidade ou retardamento mental não tivessem discernimento para a prática dos atos da vida civil e os cegos e surdos, quando a ciência do fato que ser quer provar dependesse dos sentidos que lhes faltassem. O objetivo da revogação foi a igualdade material das pessoas com deficiência, seguindo o que consta do art. 84, caput, do mesmo Estatuto, in verbis: Art. 84. A pessoa com deficiência tem assegurado o direito ao exercício de sua capacidade legal em igualdade de condições com as demais pessoas. $^{39}$

E mais, Flávio Tartuce explica o auxílio dos recursos de tecnologia assistiva, estampada no $\S 2^{\circ}$, do art. 228 , do Código Civil:

Como antes salientado, este parágrafo foi incluído pela Lei n.13.146/2015,
assegurando a capacidade civil plena para testemunhar das pessoas com deficiência,
tratando-os como iguais para tais fins. Quanto à tecnologia assistiva, ainda pouco
conhecida no País, é associada a todos os recursos e serviços que contribuem para
proporcionar ou ampliar as habilidades funcionais das pessoas com deficiência e,
consequentemente, promover a sua inclusão, social. A título de exemplo, podem ser
citados os sistemas computadorizados especiais, os programas de informática que
contemplam a acessibilidade, o uso de roupas adaptadas, a implantação de
dispositivos para adequação da postura, os recursos para mobilidade manual, os
equipamentos de comunicação alternativa, os aparelhos de escuta assistiva, as
chaves e os acionadores especiais e os auxílios visuais.

Além disso, tanto a convenção como o Estatuto da Pessoa com Deficiência preveem que o deficiente terá assegurando a capacidade de ser testemunha.

Assim prevê a Convenção no art. 13 que trata do acesso à justiça:

39 TARTUCE, Flávio. Código Civil interpretado: artigo por artigo, parágrafo por parágrafo/ costa machado, organizador, Silmara Juny Chinellato, coordenadora. - 9. ed. - Barueri, SP: Manoel, 2016, p. 255.

${ }^{40}$ Ibid. p. 256-257. 
Os Estados Partes assegurarão o efetivo acesso das pessoas com deficiência à justiça, em igualdade de condições com as demais pessoas, inclusive mediante a provisão de adaptações processuais adequadas à idade, a fim de facilitar o efetivo papel das pessoas com deficiência como participantes diretos ou indiretos, inclusive como testemunhas, em todos os procedimentos jurídicos, tais como investigações e outras etapas preliminares. ${ }^{41}$

Já o Estatuto assim assegura no art. 80:

Art. 80. Devem ser oferecidos todos os recursos de tecnologia assistiva disponíveis para que a pessoa com deficiência tenha garantido o acesso à justiça, sempre que figure em um dos polos da ação ou atue como testemunha, partícipe da lide posta em juízo, advogado, defensor público, magistrado ou membro do Ministério Público. ${ }^{42}$

No entanto, o Novo Código de Processo Civil instituído pela Lei n. ${ }^{\circ}$ 13.105/2015, vigente desde 18 de março de 2016, praticamente repetindo a lei processual revogada, prevê que aqueles que possuem alguma enfermidade, retardo ou deficiência mental, bem como os cegos e os surdos não poderam servir como testemunha, conforme preconiza o art. 447 deste diploma legal:

\footnotetext{
Art. 447. Podem depor como testemunhas todas as pessoas, exceto as incapazes, impedidas ou suspeitas.

$\S 1$ 1o São incapazes:

I - o interdito por enfermidade ou deficiência mental;

II - o que, acometido por enfermidade ou retardamento mental, ao tempo em que ocorreram os fatos, não podia discerni-los, ou, ao tempo em que deve depor, não está habilitado a transmitir as percepções;

III - o que tiver menos de 16 (dezesseis) anos;

IV - o cego e o surdo, quando a ciência do fato depender dos sentidos que lhes faltam. ${ }^{43}$
}

O Código de Processo Civil vai na contramão do estabelecido pela Convenção e pelo Estatuto da Pessoa com Deficiência, uma vez que o deficiente foi igualado as pessoas sem deficiência no que concerne à capacidade, inclusive assegurando seu direito de servir como testemunha.

O Código de Processo Civil vai na contramão do estabelecido pela Convenção e pelo Estatuto da Pessoa com Deficiência, uma vez que o deficiente foi igualado as pessoas sem deficiência no que concerne à capacidade, inclusive assegurando seu direito de servir como testemunha.

\footnotetext{
${ }^{41}$ http://www.planalto.gov.br/ccivil_03/_ato2007-2010/2009/decreto/d6949.htm. Acesso em: 15.mai.2017.

42 http://www.planalto.gov.br/ccivil_03/_ato2015-2018/2015/lei/113146.htm. Acesso em: 15.mai.2017.

${ }^{43}$ http://www.planalto.gov.br/ccivil_03/_ato2015-2018/2015/lei/113105.htm. Acesso em: 11.mai.2017.
} 
Acerca da previsão do art. 447, do novo diploma processual, Elpídio Donizetti, um dos autores do anteprojeto do Código, leciona que o Código de Processo Civil deve prevalecer sobre o Estatuto, vez que entrou em vigor após a lei do deficiente:

\begin{abstract}
O Estatuto da Pessoa com Deficiência exclui das pessoas impedidas de depor: (i) aqueles que, por enfermidade ou retardamento mental, não tiverem discernimento para a pratica dos atos da vida civil; e (ii) os cegos e surdos, quando a ciência do fato que se quer provar dependa dos sentidos que lhes faltam.

O novo CPC não revoga expressamente o disposto no art. 228 do código Civil. Apesar disso, como ele entra em vigor em março de 2016 e o Estatuto da Pessoa com Deficiência tem sua vacatio legis ultimada em janeiro do mesmo ano, a consequência é: devem prevalecer as disposições do novo CPC.

Ocorre que é necessário interpretar a lei processual em conformidade com as garantias conferidas pelo Estatuto, que claramente se propõe a dignificar a pessoa com deficiência e a promover, em condições de igualdade, o exercício de todos os direitos que são conferidos às pessoas que não possuem essa condição.

Dessa forma, se a lei processual proíbe de depor o "o interdito por enfermidade ou deficiência mental", mas o Estatuto não traz essa limitação, o ideal é que o juiz se coloque diante da seguinte premissa: se a deficiência física ou mental não comprometer o ato processual, a pessoa, ainda que tenha sofrido processo de interdição, terá condições de servir como testemunha. Para tanto, deve ser oferecidos todos os recursos de tecnologia assistiva disponíveis para que ela tenha garantido o acesso à justiça. (art. 80 do Estatuto). ${ }^{44}$
\end{abstract}

Se opondo a prevalência do Código de Processo Civil, reconhecendo que os deficientes não estão mais incapacitados legalmente para ser testemunha, Nelson Nery assim dispõe:

\begin{abstract}
Vale destacar que o conceito de testemunha incapaz foi alterado pelo EPD, consoante a alteração imposta ao CC 228, que é similar a este CPC 447. De acordo com tal alteração, as situações previstas nos incisos II e IV do $\S 1^{\circ}$, deixariam de configurar incapacidade para o testemunho, uma vez que os CC 228 , II e III foram revogados. ${ }^{45}$
\end{abstract}

Não se pode sequer sustentar qualquer critério de especialidade ou cronológico, de que o Código de Processo Civil por regular justamente o processo ou que entrou em vigência após o Estatuto da Pessoa com Deficiência, uma vez a Convenção tem natureza de direitos humanos, foi ratificada pelo Brasil em 2008 e promulgada em 2009, aprovada pelo quórum de

\footnotetext{
${ }^{44}$ DONIZETTI, Elpídio. Curso didático de direito processual civil. - 19. Ed. revisada e completamente reformulada conforme o Novo CPC - Lei 13.105, de 16 de março de 2015 e atualizada de acordo com a Lei 13.256, de 04 de fevereiro de 2016. - São Paulo: Atlas, 2016, p. 587-588.

${ }^{45}$ NERY JUNIOR, Nelson. Código de processo civil comentado. - 16. ed. ver., atual. e ampl. - São Paulo: Editora Revista dos Tribunais, 2016, p. 1157.
} 
3/5, em cada casa legislativa, foi internalizada no ordenamento jurídico como Emenda Constitucional.

Vale dizer, a Convenção sobre os Direitos da Pessoa com Deficiência possui equivalência constitucional, onde todas as demais normas infraconstitucionais devem obediência as previsões deste tratado.

Logo, o Código de Processo Civil, cuja comissão para elaboração do anteprojeto foi nomeada no final de setembro de 2009, pelo presidente do Senado Federal a época, José Sarney, e a sua confecção perdurou por aproximadamente 5 (cinco) anos, deveria convergir aos comandos da Convenção, e não contrariá-la, já que esta tem força constitucional, assegurando que o deficiente tenha igualdade de direitos com as demais pessoas e permitindo que seja testemunha em juízo como forma de efetivar o seu acesso à justiça.

Com efeito, é possível, inclusive, sustentar a inconstitucionalidade do art. 447, § 1, do Código de Processo Civil, vez que é incompatível com uma previsão constitucional que assegura a capacidade legal do deficiente.

Portanto, a limitação intelectual, mental ou sensorial não pode mais servir como vedação, por si só, para que os deficientes não prestem seu depoimento em juízo, uma vez que não são mais incapazes civilmente, devendo ser atendido os comandos do Estatuto.

Porém, enquanto a previsão do Código de Processo Civil não é revogada ou declarada inconstitucionalmente, deve o julgador, quem é o destinatário da prova testemunhal, aceitar o deficiente como testemunha e valorará seu depoimento conforme seu livre convencimento, conforme preconiza o art. 371 da legislação processual.

\section{CONCLUSÃO:}

A Convenção e o Estatuto da Pessoa com Deficiência alteraram o ordenamento jurídico, de modo que cabe ao Estado reconhecer o deficiente como capaz de praticar os atos da vida civil por si só, além de efetivar seus direitos fundamentais.

Ao alterar a capacidade civil, aboliu a limitação intelectual ou mental como razão para ser reconhecido como um incapaz absolutamente, prescrevendo apenas que o menor de 16 (dezesseis) anos assim será considerado. 
Os que não puderem exprimir sua vontade, ainda que por causa transitória ou permanente, será considerado um relativamente incapaz, mas devendo se submeter a um processo de curatela, qual afetará apenas seus direitos negociais e patrimoniais.

Assim, a pessoa com deficiência, qual seja a sua deficiência, com mais de dezesseis anos, poderá servir como testemunha em juízo, visto que é considerado capaz para praticar os atos da vida civil, cabendo ao juiz valorar o seu depoimento, mas não vedar, conforme erroneamente dispõe o art. 447, $\S 1^{\circ}$ do Código de Processo Civil.

\section{REFERENCIAS BIBLIOGRÁFICAS:}

ALTAVILA, Jayme de. Origem dos Direitos dos Povos. - $12^{\text {a }}$ edição. - São Paulo: Ícone, 2013.

ARANHA, Maria Salete Fábio. Projeto Escola Viva: garantindo o acesso e permanência de todos os alunos na escola: necessidades educacionais especiais dos alunos, volume 1. Brasília: Ministério da Educação, Secretaria de Educação Especial, 2005.

ARAUJO, Luiz Alberto David. COSTA FILHO, Waldir Macieira da. O estatuto da pessoa com deficiência - EPCD (LEI 13.146, DE 06.07.2015): Algumas Novidades. Revista dos Tribunais, vol. 962/2015, p. 65 - 80, Dez / 2015.

ARISTÓTELES, A política, tradução: Pedro Constantin Tolens, $3^{\text {a }}$ reimpressão, São Paulo: Editora Martin Claret, 2010.

DINIZ, Maria Helena. Curso de direito civil brasileiro, v. 1: teoria geral do direito civil. 23. ed. rev. e atual. - São Paulo : Saraiva, 2006.

DONIZETTI, Elpídio. Curso didático de direito processual civil. - 19. Ed. revisada e completamente reformulada conforme o Novo CPC - Lei 13.105, de 16 de março de 2015 e atualizada de acordo com a Lei 13.256, de 04 de fevereiro de 2016. - São Paulo: Atlas, 2016.

Atlas, 2014.

QUINTELLA, Felipe. Curso didático de direito civil. - 3. ed. - São Paulo,

FARIAS, Cristiano Chaves de. ROSENVALD, Nelson. Curso de direito civil: parte geral e LINDB. - 14. ed. rev., ampl. e atual. - Salvador: Ed. JusPodivm, 2016.

FACHIN, Zulmar. Curso de direito constitucional. - 3. ed. rev. atual. e ampliada. - São Paulo: Método, 2008.

FONSECA. Ricardo Tadeu Marques da. A ONU e seu conceito revolucionário de pessoa com deficiência. Revista Ltr. Legislação do Trabalho, v. 72-I, p. 263-270. 2009. 
FOUCAULT, Michel. História da loucura na Idade Clássica. Trad. José Teixeira Coelho Netto. São Paulo: Perspectiva, 1978.

GAGLIANO, Pablo Stolze. PAMPLONA FILHO, Rodolfo. Manual de direito civil; volume único. - São Paulo: Saraiva, 2017.

. É o fim da interdição?. Revista Jus Navigandi, ISSN 1518-4862, Teresina, ano 21, n. 4605, 9 fev. 2016. Disponível em: 〈https://jus.com.br/artigos/46409>.

GONÇALVES, Carlos Roberto. Direito civil brasileiro : parte geral : v 1. - São Paulo: Saraiva, 2003.

GUGEL, Maria Aparecida. A pessoa com deficiência e sua relação com a história da humanidade. Disponível em: http://www.ampid.org.br/ampid/Artigos/PD_Historia.php.

- Pessoas com deficiência e o direito ao concurso público: reserva de

cargos e empregos públicos, administração pública direta e indireta. Goiânia : Ed. da UCG, 2006.

MALUF, Sahid. Teoria geral do Estado. Atualizador prof. Miguel Alfredo Malufe Neto. 31. Ed. - São Paulo: Saraiva, 2013.

MONDAINI, Rosimery Leão. HISTÓRIA DA DEFICIENCIA E DA EDUCAÇÃO ESPECIAL: NO BRASIL E NO MARANHÃO. V Congresso Brasileiro Multidisciplinar de Educação Especial. 3 a 6 de novembro de 2009 - Londrina - Pr, p. 1618. Disponível em: http://www.uel.br/eventos/congressomultidisciplinar/pages/arquivos/anais/2009/195.pdf.

NERY JUNIOR, Nelson. Código de processo civil comentado. - 16. ed. ver., atual. e ampl. São Paulo: Editora Revista dos Tribunais, 2016.

PLATÃO, A República. Tradução Pietro Nassetti. $1^{\circ}$ edição. - São Paulo: Martin Claret. 2001

PLATT, Adreana Dulcina. Uma Contribuição Histórico- Filosófica para a análise do Conceito de Deficiência. Ponto de Vista: Revista de Educação e Processos Inclusivos, Florianópolis, SC, Brasil v. 1 - n. 1 - julho/dezembro de 1999, p. 72. Disponível em: https://periodicos.ufsc.br/index.php/pontodevista/article/view/1523.

RAMOS, Cleide. A Convenção sobre os Direitos das Pessoas com Deficiência Comentada. Coordenação de Ana Paula Crosara Resende e Flavia Maria de Paiva Vital Brasília: Secretaria Especial dos Direitos Humanos. Coordenadoria Nacional para Integração da Pessoa Portadora de Deficiência, 2008.

TARTUCE, Flávio. Direito civil, 1 : Lei de introdução e parte geral. - 9. ed. - Rio de Janeiro: Forense; São Paulo: Método, 2013.

Código Civil interpretado: artigo por artigo, parágrafo por parágrafo/ costa machado, organizador, Silmara Juny Chinellato, coordenadora. - 9. ed. - Barueri, SP: Manoel, 2016. 